\title{
Pulmonary artery sarcoma feigning pulmonary thromboembolism
}

\author{
Xiaopu Wang, Junyu Pei, Zhenhua Xing, Xinqun Hu \\ Department of Cardiovascular Medicine, The Second Xiangya Hospital, Central South University, Changsha 410011, China \\ Correspondence to: Xinqun Hu, MD. Department of Cardiovascular Medicine, The Second Xiangya Hospital, Central South University, 139 Middle \\ Renmin Road, Changsha 410011, China. Email: huxinqun@csu.edu.cn.
}

Submitted Dec 25, 2019. Accepted for publication Feb 26, 2020.

doi: $10.21037 /$ cdt.2020.03.03

View this article at: http://dx.doi.org/10.21037/cdt.2020.03.03

A 53-year-old man presented with exertional dyspnea and chest pain over 6 months, and suddenly developed hemoptysis 10 days ago. Contrast-enhanced computed tomography (CT) showed three filling defects in the main pulmonary artery, right pulmonary artery trunk and branch (Figure 1). Significant enhancement can be seen in the filling defects which grows along the vessel wall while the small vessel has no obvious embolism.
Echocardiography performed that the main and right pulmonary artery had three hypoechogenic areas, and the blood flow in pulmonary artery was obviously accelerated. There was no risk factor for embolism in patient, and no abnormality in d-dimer and lower extremity vascular ultrasonography. Pulmonary artery computed tomography angiography (CTA) showed chronic thrombosis in the main pulmonary artery, right pulmonary artery, and
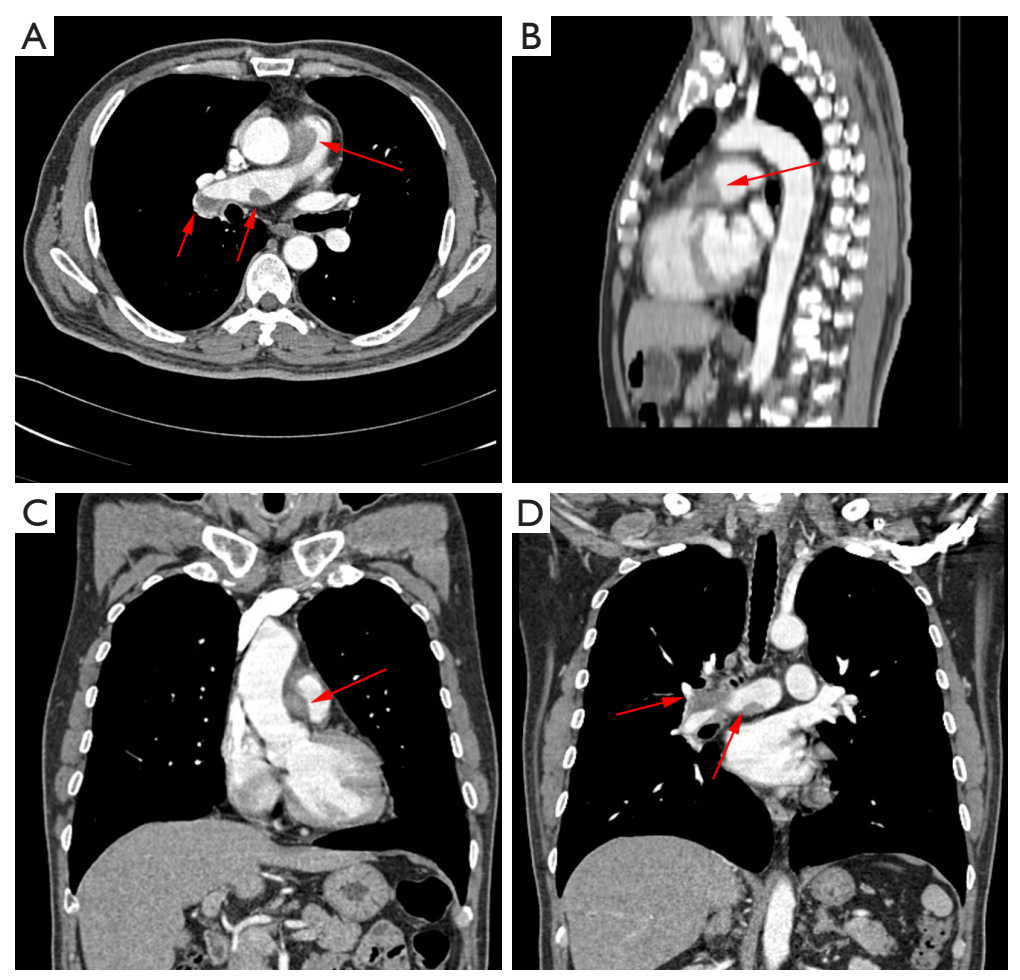

Figure 1 Contrast-enhanced CT scans showed filling detects in main pulmonary artery, right pulmonary artery trunk and branch (red arrows). (A) Transverse plane of contrast-enhanced CT; (B) sagittal plane of contrast-enhanced CT. (C) and (D) are coronal plane of contrast-enhanced CT. CT, computed tomography. 

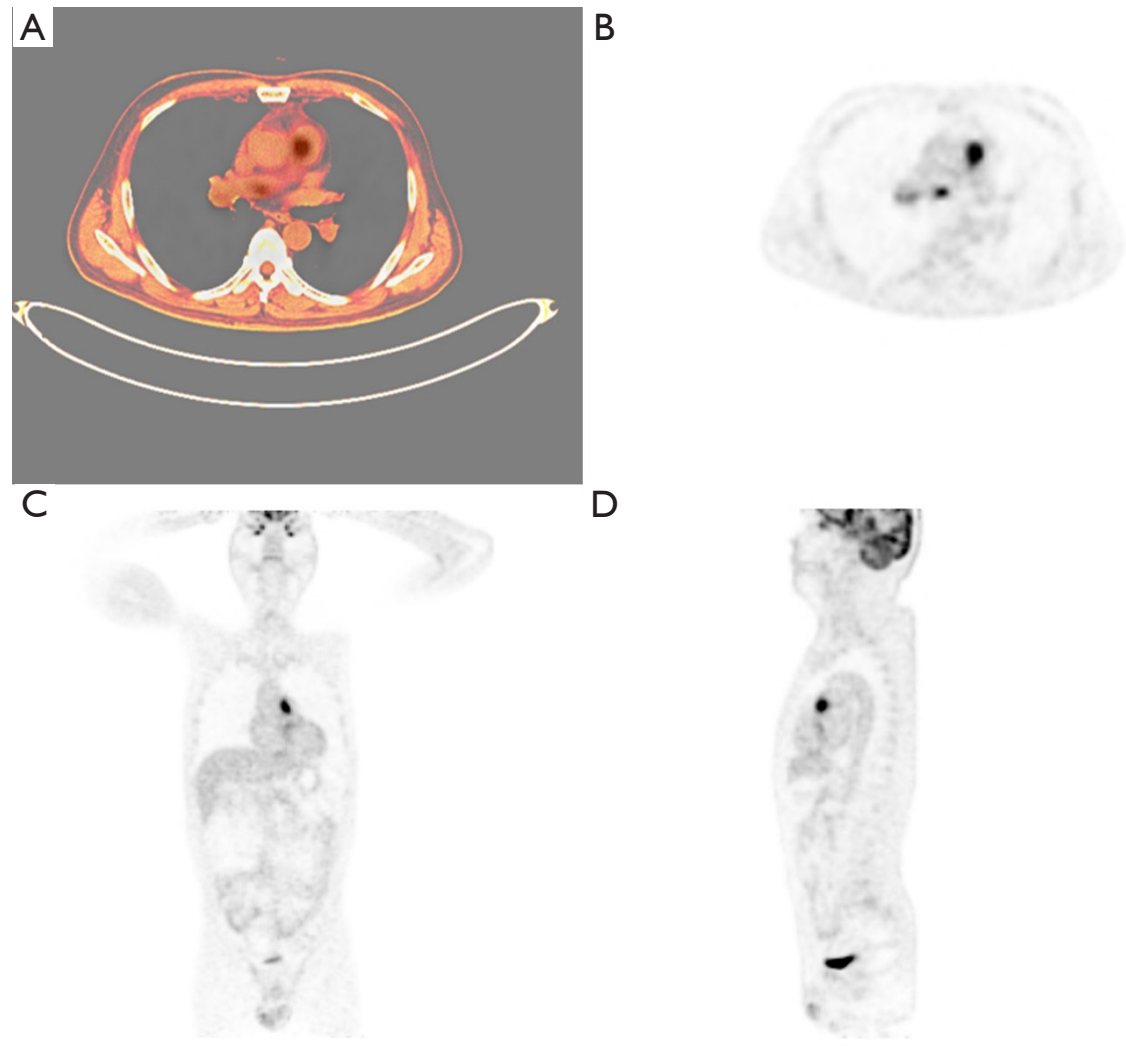

Figure 2 PET-CT scans showed a significantly increasing of SUVmax in pulmonary artery. (A) and (B) are transverse plane of fusion image and PET image; (C) coronal plane of PET; (D) sagittal plane of PET. PET-CT, positron emission tomography-computed tomography; SUVmax, standardized uptake value maximum.

branch. The lesions are large and may involve lung tissue. The lesion faces the blood flow surface full, bulging, unlike the pulmonary embolism is always a cup-shape. The result of positron emission tomography-computed tomography (PET-CT) is positive. It is performed that the size of the main pulmonary artery lesion was about $26 \mathrm{~mm} \times 23 \mathrm{~mm}$, the standardized uptake value maximum (SUVmax) value was 23.7 , the lesion of the right pulmonary artery was about $14 \mathrm{~mm} \times 20 \mathrm{~mm}$, the SUVmax value was 11.3 , the lesion size of the right pulmonary artery branch was about $16 \mathrm{~mm} \times 20 \mathrm{~mm}$, and the SUVmax value was 6.4 (Figure 2). PET is associated with abnormal increase in local glucose metabolism, therefore is considered as a primary malignant tumor of the pulmonary artery. The final clinical diagnosis of this patient is pulmonary artery sarcoma which is a rare neoplasm that appears always similar to pulmonary thromboembolism.
Pulmonary artery sarcoma is often misdiagnosed as pulmonary thromboembolism before operation or autopsy because of the lack of specificity of its clinical symptoms. In the acute phase of pulmonary thromboembolism, d-dimer is always increased. In the chronic phase, the results of CTA may indicate the reduction of vessel lumen which can be seen partial enhancement can be seen, and glucose metabolism may be increased. However, the SUVmax of lesion can't reach as high as 23.9.

\section{Acknowledgments}

Funding: None.

\section{Footnote}

Conflicts of Interest: All authors have completed the ICMJE 
uniform disclosure form (available at http://dx.doi. org/10.21037/cdt.2020.03.03). The authors have no conflicts of interest to declare.

Ethical Statement: The authors are accountable for all aspects of the work in ensuring that questions related to the accuracy or integrity of any part of the work are appropriately investigated and resolved. Written informed consent was obtained from the patient for publication of this manuscript and any accompanying images.

Cite this article as: Wang X, Pei J, Xing Z, Hu X. Pulmonary artery sarcoma feigning pulmonary thromboembolism. Cardiovasc Diagn Ther 2020;10(2):236-238. doi: 10.21037/ cdt.2020.03.03
Open Access Statement: This is an Open Access article distributed in accordance with the Creative Commons Attribution-NonCommercial-NoDerivs 4.0 International License (CC BY-NC-ND 4.0), which permits the noncommercial replication and distribution of the article with the strict proviso that no changes or edits are made and the original work is properly cited (including links to both the formal publication through the relevant DOI and the license). See: https://creativecommons.org/licenses/by-nc-nd/4.0/. 